JISTEM - Journal of Information Systems and Technology Management

Vol. 14, No. 2, May/Aug., 2017 pp. 191-218

ISSN online: $1807-1775$

DOI: $10.4301 / \mathrm{S} 1807-17752017000200004$

\title{
PROACTIVE MANAGEMENT OF IT OPERATIONS TO IMPROVE IT SERVICES
}

\section{Marko Jäntti}

University of Eastern Finland, Kuopio, Finland

Aileen Cater-Steel

University of Southern Queensland, Toowoomba, Queensland, Australia

\begin{abstract}
IT Service Operations is a high priority improvement target for IT service providers because it is critical for business operations and involves daily interaction with customers, thus directly effecting customer satisfaction. An action research project involving three organizations explored current IT service operation activities and challenges and initiated projects to improve service operation at each organization. The findings indicate that the major challenges include reactive rather than proactive approach to IT operations management, measurement and reporting, classification of incidents, management of customer feedback, and interfaces between IT service operation processes. Recommendations are formulated to help IT service managers and theoretical contributions are provided.
\end{abstract}

Keywords: IT Service Operations, Service Desk, IT Service Management, Continual Service Improvement, Proactive approach

Manuscript first received/Recebido em: 2017/Jun/19 Manuscript accepted/Aprovado em: 2017/Sep/03

Address for correspondence / Endereço para correspondência:

Marko Jäntti, University of Eastern Finland, Kuopio, Finland. E-mail: marko.jantti@uef.fi

Aileen Cater-Steel, University of Southern Queensland, Toowoomba, Queensland, Australia, E-mail: caterst@usq.edu.au ORCID ID http://orcid.org/0000-0003-2478-3129

Published by/ Publicado por: TECSI FEA USP - 2017 All rights reserved. 


\section{INTRODUCTION}

Thousands of IT service provider organizations world-wide are improving their traditional customer support processes based on IT management frameworks. The main reason for the change is that IT customers are increasingly focused on the purchase of services that support their business processes rather than separate software products (Zhang, Cai, \& Zhang, 2007). The software-as-a service business model requires attention to specific process areas that are either missing from or are not clearly visible in the traditional software maintenance processes, such as incident management, problem management and service level management. IT service providers cannot ignore IT Service Management (ITSM) processes because more and more IT customers expect evidence of a systematic service management approach from suppliers. Failure to implement ITSM may lead to lost business opportunities and lack of credibility among customers.

Organizations are interested in ITSM frameworks because they expect that implementation of best practice ITSM processes results in cost savings, reduced occurrences of incidents and increased customer satisfaction (Iden \& Eikebrokk, 2013; Mauricio Marrone $\&$ Kolbe, 2011). For example, Gartner's measurements showed that the overall results of moving from no adoption of IT Service Management to full adoption can halve an organization's Total Cost of Ownership (Koch \& Gierschner, 2007). To realize these benefits, organizations need to implement a systematic process improvement approach. Process improvement is likely to be accompanied by change resistance because the ITSM processes include new concepts that must be integrated with existing business concepts, new process roles need to be defined and deployed, and staff must be trained to use new working methods and tool functions. Therefore, it is not surprising that many process implementation projects regarding ITSM fail (Pereira \& Silva, 2011). Although the number of process frameworks, standards and models for ITSM is growing and there is a comprehensive set of best practices for implementing and improving service management processes, IT organizations still face challenges in establishing and improving ITSM. Most IT service provider organizations start their ITSM process improvement journey by adapting the IT Infrastructure Library ${ }^{\circledR}\left(\right.$ ITIL $\left.^{\circledR}\right)$ framework.

ITIL is the most widely used ITSM framework (McNaughton, Ray, \& Lewis, 2010) and covers the entire service lifecycle with five core ITSM books: Service Strategy (Cabinet Office, 2011d), Service Design (Cabinet Office, 2011b), Service Transition (Cabinet Office, 2011e), Service Operation (Cabinet Office, 2011c) and Continual Service Improvement (CSI) (Cabinet Office, 2011a). Our focus in this study is Service Operation, the objective of which is to coordinate and perform activities and service management processes in order to deliver and manage IT services at agreed levels to business users and customers (Cabinet Office, 2011a).

In addition to ITIL, there are several other frameworks that can be used to improve IT service operation such as Control Objectives for Information and related Technology $\left(\right.$ COBIT $\left.^{\circledR}\right)$ framework (COBIT5, 2012; Kerr \& Murthy, 2013). COBIT approaches ITSM from an IT governance perspective and suggests control objectives, roles and responsibilities and metrics for ITSM processes, such as managing incidents and problems (Kerr \& Murthy, 2013).

While an IT service provider's business grows and more customers need to be served, the role of the service desk and service operation processes becomes more important in 
supporting services in the live environment. Increasing volumes of service desk requests force IT service providers to be more proactive instead of continuous fire-fighting with already reported incidents. Service operation staff should be able to anticipate customer needs and respond to them effectively and efficiently (Harris, 1996). Proactive methods, such as trend analysis, preventive actions and major problem reviews are considered as an effective way to decrease the number of support requests. Unfortunately, IT service providers often focus most of their resources on reactive activities and ignore the proactive methods despite the benefits (Scott, 2003). The research problem motivating this study is that although it is recognized that a proactive approach to IT operations can deliver benefits, many IT service providers favor a reactive approach in providing support to their customers.

This paper reports the findings of a multi-case action research study of three IT service provider companies. We explored their current service operation activities and challenges before initiating a project to improve service operation at each organization.

The remainder of the paper is organized as follows. In the next section, we discuss the role of service operation within IT management. The research methodology, data collection and analysis methods are described followed by an account of the service operation methods, continual improvement methods, IT service operation challenges and process improvement actions identified in three IT service providers. The findings and emergent themes are discussed and linked to prior work. The conclusions are given in the final section along with a set of recommendations to IT service practitioners, contributions and limitations of the study, and an agenda for future research.

\section{PREVIOUS RELATED LITERATURE}

A systematic literature review was conducted as the basis to formulate the research questions. The review focused on research papers published in the areas of information systems, ITSM, software engineering, and software quality improvement. The target research papers dealt with the concepts of IT customer support, the role of service operation in IT management, and process improvement.

IT services research is multidisciplinary and has attracted the interest of researchers in fields such as information systems, computer science, software engineering, operations management and marketing (Bardhan, Demirkan, Kannan, Kauffman, \& Sougstad, 2010; Huang \& Rust, 2013). IT customer support activities have been examined in software engineering research studies that dealt with software maintenance. For example, KajkoMattsson established a conceptual model of software maintenance (Kajko-Mattsson, 1998) and presented a corrective software maintenance framework $(\mathrm{CM})$ with a problem management maturity model (Kajko-Mattsson, 2002). April, Huffman Hayes, Abran, and Dumke (2005) discussed software maintenance maturity in terms of causal analysis and problem resolution. Several studies have focused on the management of development-side defects, such as defect prevention activities (Mays, Jones, Holloway, \& Studinski, 1990), establishing a systematic defect management process (QAI, 1995), how to perform causal analysis for defects (Card, 1998) and how to document defects and problems (Hirmanpour \& Schofield, 2003).

Effective software maintenance is a critical ongoing issue for IT service providers. Software maintenance can be broadly divided into product-oriented and service-oriented 
maintenance. Niessink and van Vliet (2000) studied service-oriented maintenance and pointed out that software development results in products whereas software maintenance results in services. A more modern view of software and services is that business services (for example, an e-maintenance request to the facilities management unit) are constructed from technical services, such as database services, application services and data network services. IT customers should see the business service view of the service while technical specialists maintain a technical view that describes how the service production is performed and which configuration items contribute to provide that service.

While a number of researchers have previously dealt with IT support and maintenance from a software engineering perspective, we target our research at a less covered research area, ITSM, and explore how corrective and preventive activities are performed in ITSM. There are only a few studies to date that have examined the challenges regarding IT support processes from the perspective of ITSM. Prior research has focused on the success factors in ITIL implementation projects (Tan, Cater-Steel, \& Toleman, 2009), while other researchers have focused on ITSM process maturity (Niessink \& Van Vliet, 1998), predicting the incident management lifecycle (Caldeira \& Brito e Abreu, 2008), and integration of ITIL and CMMI ${ }^{\circledR}$ approaches for process improvement (Latif, Din, \& Ismail, 2010). Additionally, there are studies that have examined prioritization of business incidents (Barlow \& Stewart, 2004), incident management quality and productivity (Cavalcante et al., 2013) and use of knowledge management in ITIL implementations (Mohamed, Ribière, O'Sullivan, \& Mohamed, 2008).

\section{The role of service operation within IT management}

According to the ITIL framework, the service operation phase comprises five processes: event management, incident management, request fulfilment, access management, problem management; and four functions: service desk, application management, technical management, and IT operations management (Cabinet Office, 2011a). The scope of our research includes these five processes and the service desk function. In using the ITIL framework, it is important that each organization adapt these ITIL processes and functions to meet its specific IT service objectives (Al Mourad \& Johari, 2014).

A socio-technical approach is recommended for successful IT service operation based on three main elements defined in ITSM frameworks: people, process and information technology (Cabinet Office, 2011a). Skilled IT service people are needed to provide customers with service experiences. People assets can be viewed in terms of both capabilities and resources. People work in specific roles and possess experience, skills and knowledge (Cabinet Office, 2011a). In order to ensure continuous learning, IT service providers should emphasize the 'People' element through effective competence management. Managers should motivate employees to participate in ITSM training and reward them for service achievements. Training is a powerful way to decrease the change resistance of employees regarding ITSM. Additionally, prior research has found that service organizations need a service culture and this can be reinforced through training and communication (Iden \& Langeland, 2010).

ITSM is a process-oriented approach. Processes enable service management staff to measure the performance of service operation and react to identified bottlenecks. Every defined operational process should include a description of process goals, benefits, scope, key concepts, 
inputs, key activities, outputs, and metrics. The relationships to other ITSM processes should be defined and monitored.

Quality of the ITSM processes can be approached from a process capability perspective. An IT service provider may use the ITSM standard (ISO/IEC 20000) (ISO, 2010) to establish a Service Management System. In addition, the international standard for process assessment (ISO/IEC 15504-8) (ISO, 2012) can be applied to perform process improvement or determine the capability level of each process based on a six point scale: Level 0: Incomplete process, Level 1: Performed process, Level 2: Managed process, Level 3: Established process; Level 4: Predictable process; and Level 5: Optimizing process (ISO, 2004).

A major focus of service operation is the management of the IT infrastructure that underpins delivery of services. Additionally, specific ITSM toolsets are required by service operations staff. A service desk tool provides support by enabling incidents to be logged and managed. The configuration management database (CMDB) is used by many processes in the service lifecycle. Discovery and diagnostic tools are especially useful in proactive service operation management. Tools are available to monitor, control and report on infrastructure items, applications and systems as well as to capture knowledge on known errors. Instead of capturing information only on IT service components, organizations should aim to create a federated CMDB that maintains information on the whole enterprise IT infrastructure linking configuration data to other data sources, such as service desk cases and service level agreements (Markworth, 2005).

In software engineering literature, corrective and preventive actions can be typically found under one software lifecycle phase: software maintenance. One of the main difficulties in implementing ITSM processes is that they do not have a clear counterpart in software engineering. For example, most ITSM frameworks (e.g. ITIL, ISO/IEC 20000, COBIT) have distinguished incident management and problem management as separate processes. Based on the ITSM literature and best practice frameworks, we established a generic framework of service operation by including both reactive and proactive aspects of service operation as shown in Figure 1. 


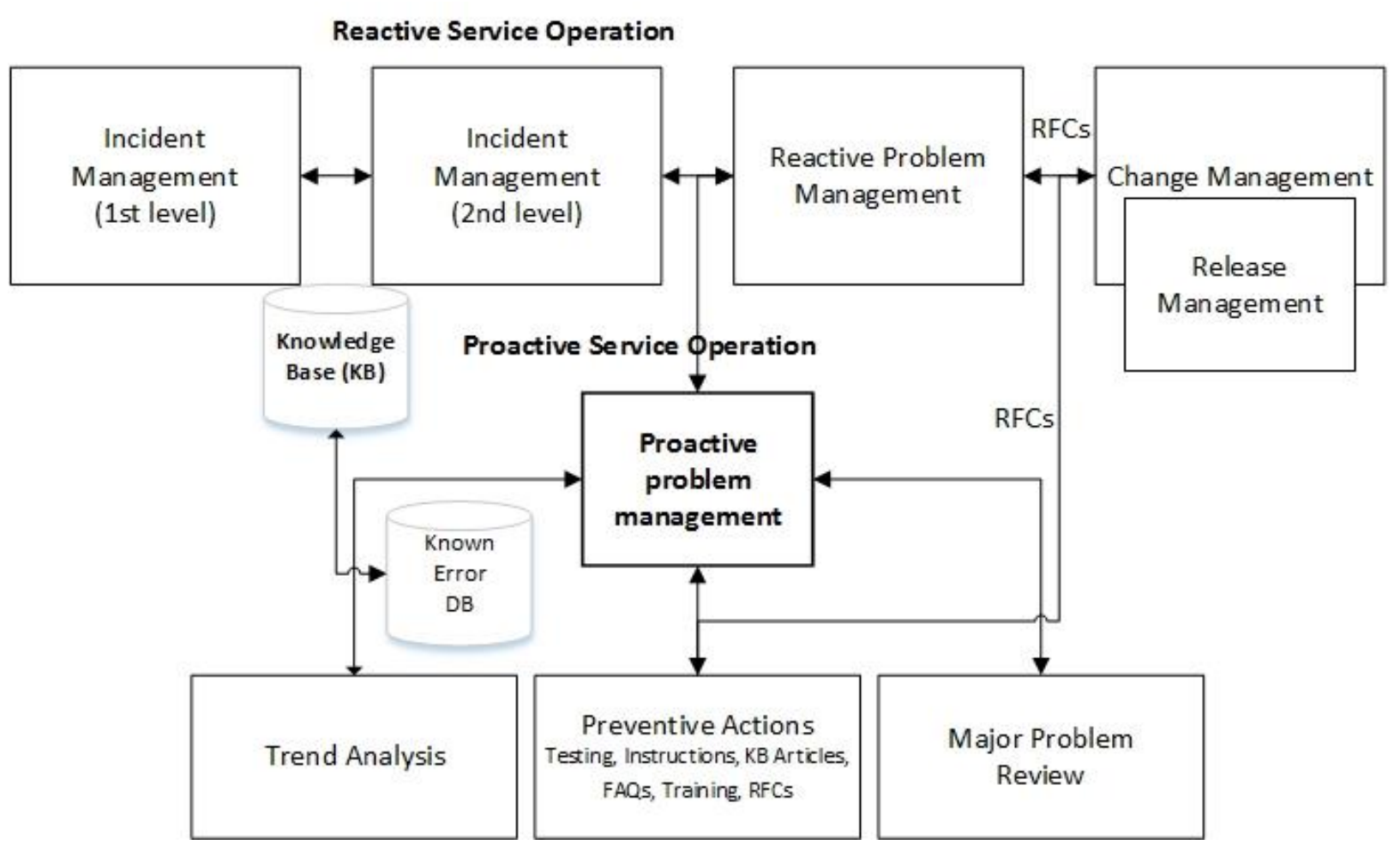

Figure 1. A generic framework of service operation

The key role of the IT service desk is to provide customers and users with a Single Point of Contact (SPOC) for the use of IT services. Services are less tangible compared to products (Bardhan et al., 2010). The intangible nature of services is addressed by the service definition of the ISO 9000 standard: "a service is the result of at least one activity necessarily performed at the interface between the supplier and customer and is generally intangible" (ISO, 2005).

Service desk responsibilities typically include responding to customers' and users' requests and queries, recording, classifying, resolving and closing incidents and informing customers on incident status and progress. In the case of a service request, the service desk may either resolve it or assign it to a dedicated service request team, depending on the organization's practices. Typically, if the service desk cannot resolve the incident, it is assigned to the second level support team (back office) that has more time and expertise to investigate the incident as shown in Figure 1. If the second level support fails to resolve the incident, the case may be assigned to the problem management team. In addition to service desk teams and support specialists, the IT Operations Bridge participates in service operation by monitoring events that are generated by automatic alerts. The IT Operations Bridge is a physical location where IT services and IT infrastructure are monitored and managed (Cabinet Office, 2011c).

More research is needed to explore the daily IT service operation practices of IT service provider organizations. If these activities do not work properly, management cannot obtain a reliable view of customer support and its resource needs. The ITSM research field could benefit from in-depth empirical studies on how IT service providers deal with the lifecycle of incidents, service requests and problems. This leads to the first research question: RQ1. How are service 
operation activities, methods and procedures performed in practice by IT service provider organizations?

\section{Process improvement}

Many business process reengineering (BPR) or restructuring studies have been conducted since the 1990s. One of the most popular BPR methods is Davenport's Business Process Redesign approach (Davenport \& Short, 1990) that includes five steps: develop the business vision and process objectives; identify the processes to be redesigned; understand and measure the existing processes; identify IT levers; and design and build a prototype of the new process. The elements of BPR can be seen in modern ITSM process improvement initiatives (Pedersen, Kræmmergaard, Lynge, \& Schou, 2010). The success of ITSM frameworks due to a shift from software production to service provision has necessitated the redesign of software maintenance processes towards ITSM. The main goal of ITSM is to ensure that the IT services are aligned to the business needs (Cabinet Office, 2011d).

Performance measurement and metrics enable organizations to achieve the objectives of continuous improvement. The organization may benchmark its current operational performance against past performance, increase the accountability of service management by defining clear and targeted process objectives for each ITSM process, increase the transparency of service operation for customers or increase the communication with customers and alignment with the overall strategy (Beath \& Straub, 1989). Researchers (Beath \& Straub, 1989) presented an IT service quality measurement framework that provides a holistic view of IT service quality. Their measurement framework contains the following service qualityrelated areas: IT service quality, information system quality, process performance, customer satisfaction, service behavior, and IT service value. Additionally, for each area, the authors described measurement categories and measures. In this paper, we deal with customer support that is located within the 'customer satisfaction' area in that framework. The importance of metrics raises the second research question: $R Q 2$. What types of methods and metrics are used for service improvement in IT operations?

Many IT service providers experience difficulties and bottlenecks in service operation processes. A range of factors have been identified that led to failure in ITIL adoption: customer dissatisfaction, additional costs for education and management, time lag in achieving benefits, conflict between urgent needs and costs, implementation difficulties, employee resistance, and lack of integration ability (Shang \& Shu-Fang, 2010). Removing these bottlenecks can enhance the IT service provider's capability to provide high quality service support to customers.

While incident management aims to restore a customer's service to a normal state as soon as possible by using workarounds if necessary, problem management focuses on identifying the root cause of incidents and proactively preventing incidents from reoccurring. According to Niessink and van Vliet (2000), IT support organizations experience issues at the interface between incident management and problem management. IT incident management requires a proactive rather than reactive approach concerning IT service continuity (Järveläinen, 2013). This is a key issue to explore in this study and leads to our third research question: RQ3. What types of challenges are faced in IT service operation? 
Continual service improvement is recognized as one of the five ITIL lifecycle phases. A variety of activities can be conducted to improve services such as measurement, reporting, customer feedback analysis, and dealing with improvement suggestions. There are two distinct approaches to IT service process improvement: provider-driven and customer-driven IT service process improvement. Provider-driven improvement focuses on the internal goals of an IT service provider organization. These improvements might be related to service production, technical infrastructure and the service management processes from the organization's internal perspective. Customer driven improvements are related to service management that is visible to customers. These improvements are typically suggested by customers and users.

Implementation of ITSM processes should be considered as an organizational change and should be conducted using project management procedures (Iden \& Langeland, 2010). Organizational change theory can be applied to ITSM to provide a roadmap for managing the change implementation. Kotter's (1996) 8-step change model has been recommended in the ITIL guidelines: 1) establish a sense of urgency; 2) create a guiding coalition; 3) develop a vision and strategy; 4) communicate the change vision; 5) empower action; 6) generate shortterm wins; 7) consolidate gains and produce more change; and 8) anchor new approaches in the culture (Cabinet Office, 2011e). Following these steps in an ITSM implementation project creates a systematic approach for leading the change and helps to alleviate change resistance. In this research, we planned a project at each organization based on Kotter's advice that was reinforced by Iden and Langeland (2010): start with and prioritize a few ITIL processes where there are greatest opportunities for success.

In this paper, we aim to probe issues related to actual improvement actions in service operation, such as establishment of proactive service management methods. Järveläinen emphasized the role of top-management support, committed business units and employees, and organizational alertness and preparedness within continuous IS operations (Järveläinen, 2013). The fourth research question explores how providers improve the quality of service operation in practice: RQ4. Can 'quick wins' be achieved for improvements to IT service operations? To address this question, we instigate a CSI project at three IT service providers. Each project is time-boxed with a set duration of one month and is carried out on a practical level as part of the IT service providers' daily business activities.

\section{RESEARCH METHODOLOGY}

The study is based on a pragmatic research philosophy with case study and action research approaches applied to answer the research questions. Action research was selected as it aims to understand, improve and reform practical situations (Baskerville, 1999) by solving a direct problem situation while carefully informing theory (Goldkuhl, 2008). Three Finnish case study organizations were invited to participate in the research project. These organizations were selected from the research group's industrial partner pool. The three case study organizations agreed to participate in the research that constituted undertaking one improvement project at each site. Each project followed the action research cycle and included four distinct phases (McNiff, 2013): 
- Phase 1. Diagnose: At the initial meeting at each organization, the principal researcher explained the aim of the overall research project and discussed the specific goals and scope of the individual projects. Due to temporal and financial constraints, the project duration was fixed at one month with a weekly review cycle. At each organization, the principal researcher conducted interviews, observed activities of service operation staff, and was provided with data in the form of reports, process documentation and archival records.

- Phase 2. Plan: In consultation with the project sponsor at each case organization, a project plan was compiled identifying selected target processes and service areas for improvement. Details such as site contact personnel, timeframes and deliverables were included.

- Phase 3. Take action: The principal researcher provided training sessions, documentation of procedures, processes, models and facilitated sessions to analyse specific issues.

- Phase 4. Evaluate action: At the completion of each project, a closure meeting was organized to summarize the process improvement results. A case study report was compiled and delivered to each project sponsor.

\section{Case selection}

The selected organizations were considered as typical cases of companies that are actively implementing ITSM processes based on the ITIL framework. The organizations are from different business domains, include different service production models (both internal and external IT service providers) but deal with the same type of IT services such as application, server, and user support services. The study was conducted from 2010 to 2015.

As the findings contain commercially sensitive information, the identities of the three organizations cannot be revealed. In this paper, they are referred to as Provider A, Provider B and Provider C. Next, a brief description of each organization is provided.

Provider A is the Information System Management unit of a government department. The unit provides IT services (e.g. workstation services, service desk) to administrative staff. Regarding the case selection, Provider A is a representative case of a government agency interested in ITIL-based process improvement. The organization had approximately 5,000 fulltime employees in 2010. The service desk improvement project commenced in the organization in 2010. Provider B provides IT services for a large bank in Finland. Provider B acts as an internal service provider and carries out ITSM process improvement. In addition to ITIL, the organization had implemented Lean improvement methods. Provider $\mathrm{C}$ is a large IT service provider organization with almost 800 staff. Provider $\mathrm{C}$ has many clients in Scandinavian countries. Provider $\mathrm{C}$ provides various types of services to its customers: application services, desktop services, hosting services, network services etc.

\section{Data collection}

Following the case study data collection principles proposed by Yin (1994), we used multiple sources of evidence to provide a richer view rather than relying on one data collection method. As shown in Table 1, evidence collected included documents (letters, minutes of meeting, user manuals, process descriptions), archival records (service records, organizational 
charts), interviews (open ended, focused, structured), observations (direct or participant observation) and physical artifacts (device, tool, instrument).

Table 1. Data Collection Methods for each Case Organization

\begin{tabular}{|c|c|c|c|}
\hline $\begin{array}{l}\text { Data Collection } \\
\text { Method }\end{array}$ & Provider A & Provider B & Provider C \\
\hline Documents & $\begin{array}{l}\text { Service descriptions, } \\
\text { process diagrams for } \\
\text { handling service } \\
\text { requests, quality } \\
\text { objectives for user } \\
\text { support }\end{array}$ & $\begin{array}{l}\text { Failure management } \\
\text { process description, } \\
\text { production process } \\
\text { model }\end{array}$ & $\begin{array}{l}\text { Audit guidelines, } \\
\text { process descriptions, } \\
\text { service desk metrics }\end{array}$ \\
\hline Archival records & $\begin{array}{l}\text { Process performance } \\
\text { statistics }\end{array}$ & Organizational charts & \\
\hline $\begin{array}{l}\text { Interviews and } \\
\text { discussions }\end{array}$ & $\begin{array}{l}\text { Operations bridge, } \\
\text { service desk, service } \\
\text { managers }\end{array}$ & $\begin{array}{l}\text { Manager of quality } \\
\text { management and } \\
\text { production support } \\
\text { unit, two production } \\
\text { support managers and } \\
\text { a quality specialist }\end{array}$ & $\begin{array}{l}\text { Interviews with } 18 \\
\text { managers (service } \\
\text { managers, process } \\
\text { managers, a quality } \\
\text { manager) }\end{array}$ \\
\hline $\begin{array}{l}\text { Participative } \\
\text { observation }\end{array}$ & $\begin{array}{l}\text { Incident workshop; } \\
\text { problem } \\
\text { management } \\
\text { workshop; ITSM } \\
\text { training sessions }\end{array}$ & $\begin{array}{l}\text { Four work meetings; } \\
\text { two ITSM training } \\
\text { sessions }\end{array}$ & $\begin{array}{l}\text { Work meetings \& } \\
\text { information sharing } \\
\text { meetings }\end{array}$ \\
\hline Physical artifacts & $\begin{array}{l}\text { Access to the service } \\
\text { desk tool and intranet }\end{array}$ & $\begin{array}{l}\text { Organization's } \\
\text { intranet, ITSM tool } \\
\text { presentation }\end{array}$ & $\begin{array}{l}\text { Access to the } \\
\text { organization's } \\
\text { intranet, service desk } \\
\text { tickets }\end{array}$ \\
\hline
\end{tabular}

\section{Data analysis}

To conduct the case study analysis, we used three techniques: pattern matching, explanation building, and cross-case synthesis. The pattern matching technique involved comparing empirical patterns identified during a case study with a predicted pattern. ITIL was used as a kernel theory providing the predicted pattern. In addition to triangulation of data from multiple sources (Yin, 1994) we used researcher triangulation (multiple investigators studied the same target and analyzed the findings). Cross-case analysis techniques (Eisenhardt \& Graebner, 2007) were used to search for cross-case patterns and compare findings from the three case organizations. The principal researcher compiled a narrative for each provider summarizing the evidence from the interviews and the other researchers reviewed and refined the narratives. During the analysis of cases, we created matrices to summarize and report the 
qualitative factors (Huberman \& Miles, 1994). Finally, we collaborated to extract themes using an interpretive lens to consider the context to allow themes to emerge (Trauth \& Jessup, 2000).

\section{RESULTS}

The following subsections describe our findings on service operation processes in the three organizations studied. The findings are organized to answer the four research questions.

\section{RQ1. How are service operation activities, methods and procedures performed in practice by IT service provider organizations?}

Provider A. The User Support Services unit performed the service operation processes by providing support services for the use of the information technology and management of the production environment. There were several groups in geographically distributed locations responsible for handling incidents and service requests in the case organization.

The first-level support was provided by the service desk. Remote support operated on first and second level and handled incidents. The Operations Bridge function managed and coordinated the investigation of infrastructure related incidents. The Operations Bridge also performed activities such as informing of production failures, monitoring data transfer, and recording error messages and events with automatic alerts from the IT infrastructure. The application support team was responsible for providing user support regarding applicationrelated questions. The user rights management team was responsible for creation of user names and passwords and configuration of access rights for applications and folders.

Incidents and service requests were recorded and classified by the service desk staff. Users were provided with support documentation on the intranet. The main service channels for users were phone and the service desk system. Classification of each service desk case required selection of a customer, service, contact method, reason for contact and update of the status. Service Level Agreements (SLAs) were not used in Provider A although target resolution times were defined for cases.

Provider A did not have a well-defined problem management process or a problem record because incident management was the primary goal on commencement of the ITSM project. However, we found a large number of well-documented procedures on error and request handling that provided the research team with a good overview of how Provider A's IT service operation worked in practice. We observed that Provider A used the service desk function and the following processes: incident management; request fulfilment; and access management. The application management function was performed by the application support and application technology teams. Additionally, the Operations Bridge seemed to perform event management activities but these were not conducted as a systematic process.

Provider B. Provider B's internal customers are employees of banks and insurance companies. The first-level support was carried out mainly by five units: process services (bank service processes, customer service support), user support team, the service desk of the IT provider and the insurance business hotline. Incidents were reported by internal and external customers, employees, management and third party providers. An incident might be, for 
example, an error in the online bank service. Incidents were recorded by using the ITSM tool. Provider B used a 4-level priority scale (low, normal, high, very high) for incidents. We observed that there were no service level agreements in use or visible in service desk cases although goal response times and resolution times were defined for service requests.

At Provider B, we observed the use of a crisis communication procedure that was very close to ITIL's major incident procedure. Cases were escalated based on four different procedures: application incidents were assigned to IT operation services or the Support Service team; system-related incidents to an IT service provider or IT delivery teams; hardware-related incidents to field support; and detailed investigations to an IT service provider when there was insufficient information on the incident. We also observed that Provider B had clearly defined communication channels (intranet, SMS, mailing lists) and communication responsibilities to inform customers and users of incidents. Examples of service requests in Provider B were workstation installations, maintenance and field support orders. Although Provider B recorded incident and problem records in the ITSM tool, it appeared to lack service management process descriptions for incident, service request and problem management. Similarly to Provider A, B had documented procedures to handle different types of incidents.

Provider B had a failure investigation procedure and some incident management procedures that were performed by the organization's help desk. Request fulfilment and access management were based on informal procedures. The organization had created a problem record to prepare for implementing problem management. Application management was performed by an application support team, a subcontractor, and an external service provider. Regarding event management, the application support team was responsible for monitoring insurance applications.

Provider C. Customers of Provider C were provided with multiple channels for support: phone, email or by creating an incident request using the web portal. Incident management had been divided into three levels: first level was responsible for communicating with customers and recording the service desk contacts; second-level had specialized technical know-how but was not responsible for taking phone calls from customers; and third-level specialists had deeper technical expertise and participated in planning and implementing changes for customers. Each service desk team was responsible for specific customers. However, if a team had inadequate resources, other teams may receive incidents from that team.

When a customer called the service desk, the service desk representative checked whether the customer's contact details were correct and checked the customer's activity history (both incidents and service requests). The system updated the affected end user details automatically with the service desk case ticket and a support staff member entered the incident description in the incident record. Incident classification included the selection of an appropriate Service Level Agreement, incident area and configuration item. Escalation of incidents was done by selecting group or assignee data fields. A priority code for service desk cases was calculated automatically based on the impact and urgency of cases. However, emergency priority codes must be selected manually. Resolutions for cases were typically done by searching solutions from previous incidents and requests, intranet, or asking colleagues. Customers were able to check the incident status through the customer portal. Provider $\mathrm{C}$ had a problem management process and problem records in daily use and clearly defined roles and responsibilities for managing problems in different service areas. 
RQ1 Summary. Based on the information collected, the researchers considered the IT operations process attributes for level 1 (process performance) based on the international standard for process assessment. We estimated the level of achievement of the process attributes on a scale: not or barely achieved; partially achieved; largely achieved or fully achieved (ISO, 2012). The estimated process capability ratings are shown in Table 2. According to our observations, compared to Provider A and B, Provider C had the most mature IT operations processes.

Table 2. Service operation processes: extent of achievement of process attributes

\begin{tabular}{llll}
\hline Process & Provider A & Provider B & Provider C \\
\hline Incident management & Partially & Partially & Largely \\
Problem management & Not achieved & Partially & Largely \\
Access management & Not achieved & Not achieved & Partially \\
Request fulfilment & Partially & Partially & Largely \\
Event management & Partially & Partially & Partially \\
\hline
\end{tabular}

RQ2. What types of methods and metrics are used for service improvement in IT operations?

Provider A. Continual improvement regarding service operation was based on effective measurement of customer support and feedback collection. Feedback was collected frequently from staff and customers at Provider A. Customers were able to give feedback on service desk case resolutions. Feedback could be recorded on a quantitative scale or open text. Service desk and support engineers could also record feedback using the service desk tool. The service manager of user support services analyzed the feedback and initiated improvement actions.

Provider B. We identified a role of 'improvement owner' at Provider B that was responsible for continual improvement, such as identifying improvement areas. Employees may report the improvement ideas regarding processes to those improvement owners who subsequently presented them to the CSI steering group. The steering group directed the continual service improvement activities and decided annually on where improvements should be focused and improvement goals. Managers of Provider B had also used the Lean Six Sigma approach to improve the performance of specific processes, such as workstation deliveries to users. Additionally, feedback was collected on projects and the number of formal complaints was monitored. Improvement ideas and technical changes were handled in the ITSM system or logged into a crowd-innovation tool.

Provider C. Customer feedback and formal complaints on Provider C's IT services came from customers through customer service managers who contacted the production managers as part of the service level management process. A documented investigation was conducted for each complaint and feedback was discussed in groups in order to identify the 
root cause and corrective actions. There was a documented process for managing feedback. Provider $\mathrm{C}$ frequently used external auditors to benchmark its service operation processes (service desk, incident management and problem management) and applied the Plan-DoCheck-Act philosophy to ITSM.

RQ2 Summary. Across the three cases, service improvement is primarily triggered by customers. The measurement of service operation processes was performed collecting customer feedback and the following metrics:

- Number of opened and closed service desk cases by type

- Number of major incidents per month

- Number of phone calls to service desk (called, answered, missed)

- Service desk case resolution rate

- Number of SLA breaches

- Number of service desk cases by submission channel

- Number of service desk cases per person per team

- Call response time

- Service desk case resolution time

- Service desk cases per customer's business unit

- Number of problems per service area

- Average problem resolution time.

RQ3. What types of challenges are faced in IT service operation?

As shown in Table 3, the analysis of the individual cases identified a variety of challenges. 
Table 3. Service operation challenges identified in case studies

\begin{tabular}{|c|c|c|c|c|}
\hline Challenge & $\mathbf{A}$ & $\mathbf{B}$ & $\mathbf{C}$ & Data source $^{a}$ \\
\hline Measurement of incident and problem management & $\mathrm{X}$ & $\mathrm{X}$ & $\mathrm{X}$ & $\mathrm{D}, \mathrm{ID}$ \\
\hline Cooperation and interfaces ITSM processes & $\mathrm{X}$ & $\mathrm{X}$ & $\mathrm{X}$ & $\mathrm{D}, \mathrm{O}, \mathrm{ID}, \mathrm{ST}$ \\
\hline Classifying support requests is difficult & $\mathrm{X}$ & $\mathrm{X}$ & $\mathrm{X}$ & $\mathrm{O}, \mathrm{ID}, \mathrm{ST}, \mathrm{PA}, \mathrm{AR}$ \\
\hline Challenges in service operation terminology & $\mathrm{X}$ & $\mathrm{X}$ & $\mathrm{X}$ & $\mathrm{O}, \mathrm{ST}$ \\
\hline Support is too reactive & $\mathrm{X}$ & $\mathrm{X}$ & $\mathrm{X}$ & ID, PA, D \\
\hline Lack of rules how to handle reopened cases & $\mathrm{X}$ & $\mathrm{X}$ & & ID \\
\hline Lack of a problem manager & $\mathrm{X}$ & $\mathrm{X}$ & & ID \\
\hline Need for better change reporting & $\mathrm{X}$ & & $\mathrm{X}$ & ID \\
\hline Not enough time to record support cases & $\mathrm{X}$ & & & ID, ST \\
\hline SLA breached at the 2 nd level & $\mathrm{X}$ & & & ID \\
\hline Major incident concept unclear & & $\mathrm{X}$ & & ID \\
\hline No responsible person for service feedback & & $\mathrm{X}$ & & ST, ID \\
\hline Customers/users have many contact points & & $\mathrm{X}$ & & $\mathrm{AR}, \mathrm{O}, \mathrm{ID}$ \\
\hline Lack of problem management procedures & $\mathrm{X}$ & & & $\mathrm{PA}, \mathrm{O}, \mathrm{D}, \mathrm{AR}$ \\
\hline Poorly documented problem sources & $\mathrm{X}$ & & & ID, ST \\
\hline Informing Service Desk on problem solutions & $\mathrm{X}$ & & & ID \\
\hline Customer feedback not delivered to staff & & & $\mathrm{X}$ & ST \\
\hline Too much manual work in creating reports & & & $\mathrm{X}$ & ID \\
\hline Lack of unified support practices & & & $\mathrm{X}$ & ID \\
\hline
\end{tabular}

Legend. ${ }^{\mathrm{a}} \mathrm{AR}=$ Archives and records; $\mathrm{D}=$ Documentation; $\mathrm{ID}=$ Interviews and discussions; $\mathrm{O}=$ Observation; $\mathrm{PA}=$ Physical artefacts; $\mathrm{ST}=$ Seminars and training

Our findings revealed that common challenges reported by all three cases were in measurement of service operation processes, clarification of the interfaces and relationships between service operation processes and other ITSM processes, definitions of core metrics for support, classification of service support requests and a reactive approach to customer support. 
The findings also show that among the three cases, Provider $\mathrm{C}$ reported fewer challenges and appeared to have the most mature service operation processes. One clear reason for this could be that Providers A and B had commenced service operation process improvement more recently than Provider C. Providers A and B shared several of the identified challenges: lack of rules how to reopen closed incidents; lack of a designated problem manager; and the need for more effective reporting of changes. Our case studies also revealed challenges that were unique to individual organizations, such as lack of problem management procedures in Provider A, the large number of contact points in Provider B and a high level of manual work in compiling reports at Provider C.

\section{RQ4. Can 'quick wins' be achieved for improvements to IT service operation?}

Provider A. A workshop was held to discuss how problem management could be improved. A scenario-driven approach was used based on five actual incidents that had resulted in extensive resolution times. The existing incident and error handling process was analyzed and compared to an ITIL-based 'ideal' process. Using actual cases showed that many stakeholder groups may participate in the resolution process. Consequently, identifying similar incidents and relating them to one problem is not simple in practice. The problem management improvement workshop focused on identifying the sources of problems, customizing the problem record and discussing how the problem solution knowledgebase should be implemented. Additionally, service operation metrics, KPIs and CSFs were discussed in the measurement workshop. ITSM training sessions were conducted in five different cities. An ITSM introduction training session to increase the staff's awareness of ITSM concepts was followed by a training session that covered incident, problem, change, release management and CSI. In total 50 IT support and product development specialists participated in training sessions. The process improvement project resulted in:

- Identified challenges regarding problem management and improvement suggestions

- Documented list of potential problem sources

- Documented list of planned future tool-related improvements

- Documented procedure how to use the ITSM tool to manage problems.

Provider B. The ITSM process improvement commenced with the researcher conducting interviews and discussions with the IT service manager on the current state of IT support. Existing documentation on service operation practices (incident and service request management) was analyzed. Documented service operation practices and interview results were used to establish a process description of incident and service request management processes. The second improvement target was to help Provider B describe application support services. A one-day ITSM training workshop was conducted for about 30 staff. This training session focused on the entire ITIL lifecycle. To summarize, the following ITSM process improvement actions were performed at Provider B:

- Documented process descriptions for incident and service request management

- Customer support reorganized to a 3-level service support model 
- Selection of key process metrics for incident, problem, and change management and metrics linked to critical success factors

- Documented description of the application support service.

Provider C. In conjunction with three managers at Provider C (quality and process manager, service manager and production manager) the researcher facilitated the creation of a step-by-step CSI model based on ITIL guidelines. In this initiative, the focus was to optimize the use of service operation processes that had been created earlier. For example, a problem management process description had been in use for four years. The following process improvement activities were achieved at Provider C:

- CSI process model developed

- Documentation of guidelines on how CSI methods support service operation

- Strength-weakness-opportunity-threat (SWOT) analysis performed for ITSM

- Suggestions provided on how Provider C could improve CSI activities (measurement, service feedback collection).

RQ4 Summary. Although the scope of each improvement project was constrained by a four-week time-box and limited resources, quick wins were evident in all cases. Staff from all three organizations participated in workshops that resulted in a deeper understanding of current processes and challenges. New documentation of processes was compiled and staff at Provider A and B attended formal ITSM training sessions.

\section{DISCUSSION OF FINDINGS}

In this section, we bring together the findings to answer the four research questions to address the research problem and to link our findings to previous literature. Further analysis with an interpretive lens resulted in the emergence of themes that are discussed.

\section{Research questions}

The first research question explored how service operation activities, methods and procedures are performed in practice by IT service provider organizations.

The kernel theory that underpins this study is the ITIL framework and the theory-based concepts of ITIL were visible in three cases. All three case organizations were committed to use of the ITIL guidelines as a reference to define the processes and functions essential for IT service operations. In Table 2, we showed the extent to which the service operation processes were performed. The processes that showed the lowest level of capability were access management and event management. This could possibly be due to fact that these processes are additional processes in ITIL v3 and did not exist in the previous ITIL version. Mapping the findings to our generic framework for service operation, we observed that organizations had difficulties especially with proactive aspects of service operation (see shaded areas in Figure 2), not only in major problem reviews (dark grey areas in the framework), but also with defining preventive actions (light grey areas in the framework). 


\section{Reactive Service Operation}

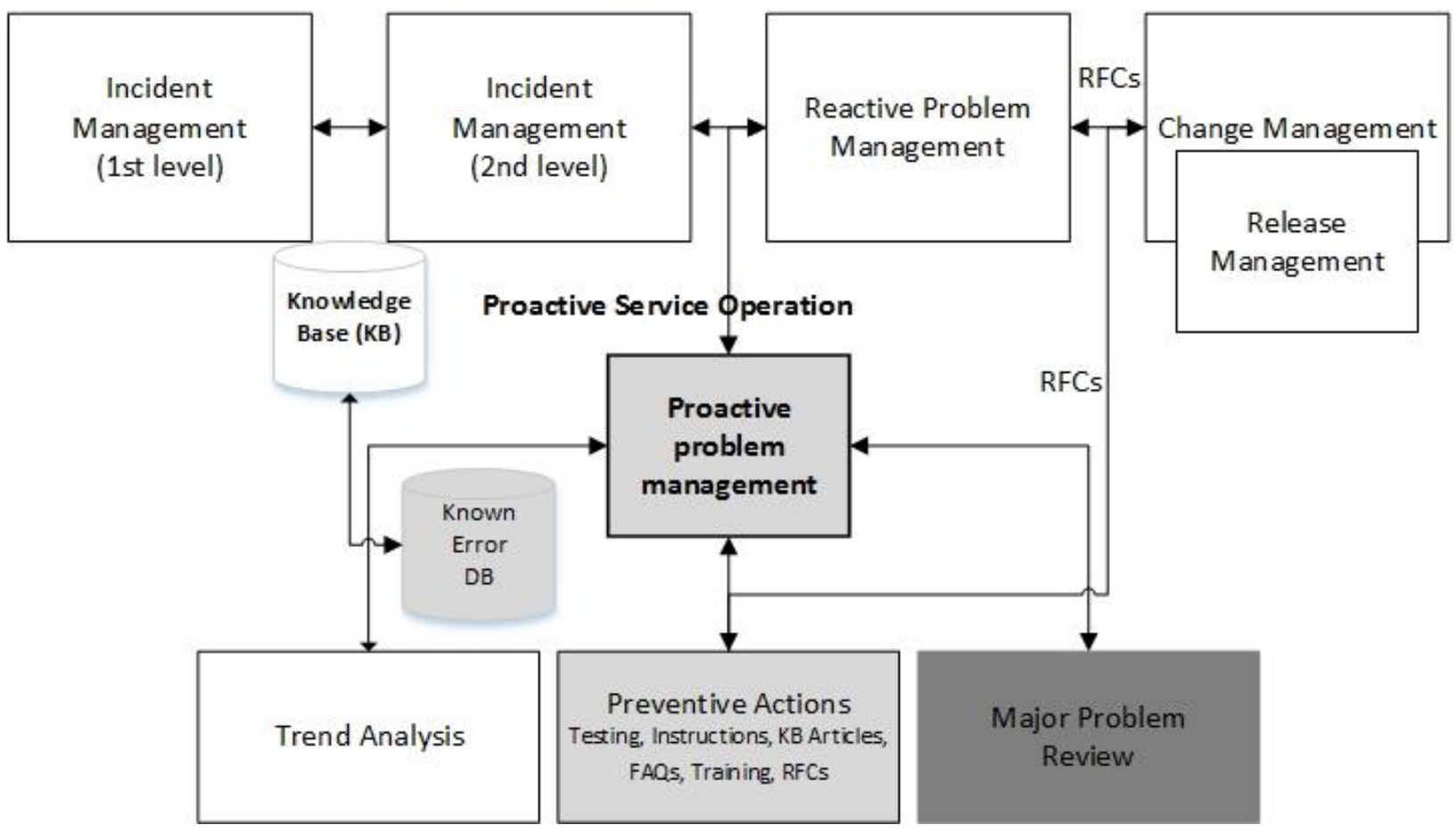

Figure 2. Challenging areas in service operation

It is clear that the current service operation activities, methods and procedures are mainly focused on reactive problem solving rather than proactive efforts to prevent the occurrence of service outages. This situation may be due to the fact that ITIL provides limited advice on proactive methods. Our findings support previous research by Shang and Shu-Fang (2010) who found that factors such as lack of resources and resistance to change stymy process change initiatives.

Each service provider had adapted and used an ITSM-compliant tool to support the service desk. There were no remarkable differences in incident records although Provider B's incident record was clearly designed for logging specific details of bank and insurance customers and included data fields specific to banking and insurance applications. Provider C was the only organization that had formal SLAs in place. The problem management process had been defined and implemented at Provider $\mathrm{C}$ for some years whereas Provider $\mathrm{A}$ and Provider B had recently commenced the definition of the problem management process. Therefore, Provider $\mathrm{C}$ was more interested in measurement, reporting and continual improvement of service operation than implementing service operation practices. However, all three organizations considered continual improvement methods important and participated in CSI workshops.

The types of methods and metrics used for service improvement in IT operations was the focus of the second research question. In all three cases, improvements are mainly driven by customer feedback, in particular by incidents. Provider B's approach had been formalized with the appointment of a staff member responsible for improvements and the organization's use of the Lean Six Sigma quality approach. As Provider C had SLAs in place, feedback from customers was gathered as part of the service level management process. Furthermore, Provider 
$\mathrm{C}$ engaged external auditors to conduct benchmarks of its service processes. The use of an ITSM tool by all providers facilitated the collection of metrics based on service desk records however the collected metrics were not effectively used to drive improvements.

Unresolved incidents were formally managed and escalated to problem management. There was limited use of alert software to generate warnings of infrastructure events. Based on the interviews, there was minimal evidence of proactive steps to search for root cause of repeating incidents, the establishment of a known error database with work arounds, performance of trend analysis, definitions of preventive actions (testing, raising RFCs, providing instructions), or major problem reviews.

In terms of formal approaches to improve service management processes, only Provider $\mathrm{C}$ appeared to be undertaking business process reviews as advocated by Pedersen et al. (2010). Although all service providers were responsive to the immediate needs of their customers, there was no evidence found of any efforts to align services and processes with the business needs of the IT Service Provider or customers.

The third research question considered the types of challenges faced in IT service operation. The challenges identified can be broadly grouped into measurement and management issues. The lack of definitions of core metrics resulted in difficulties in measuring the performance of the service operation processes. Associated with this is the requirement for clear and consistent classifications of service support requests.

The management issues relate to the internal structure and the priority given to resource reactive support at the expense of proactive behavior (Orta, Ruiz, Hurtado, \& Gawn, 2014). For example, two of the service providers had not established the formal role of a problem manager or problem management process owner. In addition, management needs to ensure that effective communication is established between the individual teams of support and technical staff. This would help clarify the interfaces and relationships between service operation processes and other ITSM processes such as change and release management.

The challenges reported are consistent with those found in prior studies on ITIL implementation: difficulties in measuring and reporting ITSM outcomes (Gacenga, CaterSteel, \& Toleman, 2010); the importance of process integration (Beath \& Straub, 1989; Shang \& Shu-Fang, 2010); proactive orientation to incident management (Järveläinen, 2013); classification of incidents and service requests as well as identification of problems (Jantti, Rout, Wen, Heikkimen, \& Cater-Steel, 2013). Our findings also confirm the view of Niessink and van Vliet (2000) that IT support organizations experience issues at the interface between incident management and problem management.

The final research question was explored by an improvement project at each organization to establish whether 'quick wins' could be achieved for improvements to IT service operation.

Despite the time- and resource-limited scope of the three projects, significant improvements were realized in terms of workshops, documentation of processes and models, and professional development of IT operations staff. The comments from the project sponsors were positive and indicated that interest in further improvement projects had been ignited. This response confirms the approach and value of commencing with achievable, tightly scoped 
projects to ensure cooperation of affected staff (Iden \& Langeland, 2010; Kotter, 1996; Pedersen et al., 2010).

As this study included active involvement of the principal researcher, the motivating influence of this person needs to be mentioned. Prior studies on ITIL adoption have found that initiatives benefit from the involvement of an expert external consultant (Iden \& Eikebrokk, 2013). This may be because existing staff typically do not have the expertise, time or authority to initiate change programs. However, engagement of external consultants is fraught with challenges (e.g. can be expensive and lead to resistance from staff).

Especially from the perspective of CSI, demonstrating 'quick wins', opportunities for improvement that are relatively easy and inexpensive to implement (Cabinet Office, 2011a) play an important role in ITSM. In Provider A, B and C, quick wins included definitions of procedures, problem records, incident and service request classification models and other work products that demonstrated that improvement activities are showing results. The differentiation of customer-driven and provider-driven quality improvement initiatives was discussed by (Heikkinen \& Jäntti, 2012). In our study, all three improvement initiatives were provider-driven and addressed the importance of demonstrating short term wins. These 'quick wins' enabled the service providers to consider how they could respond better to customer feedback and importantly how to take a more proactive approach to IT service operations.

\section{Emerging themes - Service operation}

The themes that have emerged can be aligned with the three main sociotechnical elements for successful change to IT service operation: process, technology and people (Cabinet Office, 2011c).

Theme 1. Process. It has been claimed that the previous version of ITIL (v2) tended to cause a process silo effect that prompted the restructure of the framework into a life-cycle model to avert this danger. However, it appears that when processes are defined, insufficient attention is still paid to consideration and mapping of how the processes inter-relate. ITIL provides detailed guidance on process dependencies but in practice it can be a challenge to achieve cross-team agreement on work products and work flow.

Furthermore, previous research has established that organizations typically do not implement all processes at the same time and to the same level of maturity (M. Marrone, Gacenga, Cater-Steel, \& Kolbe, 2014). For example, Provider A and B had not implemented service level management to the point of establishing SLAs with customers. SLAs would have ensured that feedback from customers may be at a more strategic level and would prompt the service provider to undertake proactive planning and changes. The findings provide support to the concept that process capability leads to organizational maturity. The feedback from these providers seems to indicate that until processes are performed, defined, managed and resourced, it is difficult to select appropriate metrics and only then is it possible to undertake effective continual process improvement (Cabinet Office, 2011a).

In ITIL, the CSI lifecycle phase urges providers to improve services and the processes that deliver services. A number of frameworks exist to help: services can be improved by applying the SERVQUAL model (Parasuraman, Berry, \& Zeithaml, 1991) to identify service gaps, while the international standard for process assessment can be used to rate process 
capability and provide recommendations for improvements (ISO, 2012). Previous ITSM studies have provided evidence that improvement in processes (e.g. through use of ITIL) has resulted in improvement in services in terms of reduced system downtime and improved customer satisfaction (Gacenga et al., 2010). The response to the research project showed that all three providers had keen interest in the improvement initiative. This interest could be nurtured with additional training in CSI and service reporting.

Theme 2. Technology. It is clear that the Service Desk tool plays an integral role in IT service operations. Effective use of ITSM tools facilitates the collection of metrics. However, the sheer volume of data collected can be overwhelming and effort is required to tailor the reports to carefully define information that is useful for IT service staff and management. ITSM tools are vital for service operation and need to be integrated e.g. CMDB and IT service desk tools (Markworth, 2005). Knowledge base resources were recognized as important by all three providers. Provider C found self-service support lacked effectiveness because customers did not find it useful due to categorization problems. This outcome adds to the findings of Walker, Craig-Lees, Hecker, and Francis (2002) who examined technologically-facilitated service delivery and found adoption or rejection was moderated by the personal capacity and willingness of individuals.

Theme 3. People. In our study, we observed that the internal service providers (Providers A and B) had significantly more complex service support structures than the external service provider, Provider C. However, Provider A and Provider B were also significantly larger organizations than Provider C.

Previous research (Pollard \& Cater-Steel, 2009) on successful ITIL adoption highlighted the need for managerial instruments such as organizational restructuring and the definition of new roles and processes to be backed up by appropriate communication that provides a rationale for the changes, sets the context and draws people in. Also highlighted is the importance of willingness to work collaboratively to define the links between processes. Providers A and B had not appointed a staff member to take responsibility for problem management. This may have contributed to the finding that problem management was not given priority. A previous study by Hochstein, Zarnekow, and Brenner (2005) suggested that the greatest challenge faced in an ITIL implementation, as in service process improvement, concerns overcoming the lack of acceptance of new processes and the lack of understanding why such changes are necessary.

Regarding the 'people' element, our findings emphasize the need for training that focuses on clarifying the service operation concepts as well as teaching staff how to classify support requests according to the provider's ITSM procedures. This study also raises the question of the importance of external change agents hence confirming prior research on ITIL adoption (Iden \& Eikebrokk, 2013). 


\section{CONCLUSION}

Our main objective was to focus on the research problem that many IT service providers rely on reactive approaches in providing support to their customers. To explore this problem, we determined the activities and processes in place in three IT service providers, the challenges they face, and their actions to improve the IT service processes and outcomes. An action research approach with three case study organizations was used as a main research method.

First, we showed the similarities and differences regarding three organizations' service operation methods. Differences were found especially in the use of SLAs and problem management. Second, we explored continual improvement in service operation. Examples of continual improvement methods included collection of feedback on service desk case resolutions, use of Lean Six Sigma methods to remove bottlenecks in ITSM processes, application of the Plan-Do-Check-Act philosophy, and benchmarking service operation processes.

Third, according to our findings, the key service operation challenges were related to measurement and reporting (e.g. too many metrics and reports in the organization, lack of metrics for problem management; the high level of manual work in producing reports), classifying incidents (separating incidents, service requests and problems), challenges related to managing feedback (lack of designated responsibility to process feedback, unclear feedback reports), and interfaces between IT service operation processes (informing service desk on problem resolutions, escalation of incidents).

Finally, we provided a short overview of the process improvement actions that were performed during the action research project within these organizations.

\section{Managerial implications}

Based on the case study findings, we derived the following recommendations to IT service providers.

Recommendation 1: Improve classification and categorization of incidents. We observed that classification of a service desk case typically includes two steps: decide if the case is an incident or a service request; then select the service area, configuration item, and appropriate service level agreement. Poorly implemented classification and categorization can decrease the performance of service desk teams and cause problems in service measurement due to incorrectly classified service desk cases.

Recommendation 2: Select key service operation metrics and reports for processes. In each case, we observed a high number of reports is produced, e.g. for different IT steering groups, resource planning processes, measurement of the support request volumes and throughput times, costs of IT maintenance, and resource availability. It is recommended to use 3-4 key metrics for each process and report them linked to key performance indicators and critical success factors. 
Recommendation 3: Ensure that feedback on service operation is frequently reviewed. It is quite surprising that organizations encounter situations where no-one is actually responsible for reviewing the customer feedback. Some employees reported that these situations might happen especially after organizational changes. There was also an interesting finding that relevant staff do not consistently receive vital customer feedback. Both positive and negative feedback should be managed in a systematic manner and reviews should check whether customer feedback has been analyzed and appropriate actions based on feedback have been taken.

Recommendation 4: Implement a Single Point of Contact service desk. A large number of contact points may be confusing from a customer's perspective and increase the amount of extra work when misrouted incidents and service requests need to be assigned to the correct team or staff member.

Recommendation 5: Provide training to service desk workers with practical examples to use ITSM concepts. Based on our case study observations, employees understand the basic meaning of the ITIL concepts quite well but difficulties occur in classifying support requests under these concepts. Especially challenging was the identification of differences between incidents, problems, change requests and service requests. Second level support specialists should be trained to open problem records with or without an incident. This challenge has been recognized in updates to ITIL: the latest version (v3) has split incident management to include three additional processes: request management, access management and event management.

Recommendation 6: Managers should promote proactive service operation and allocate adequate resources to it. A good example of proactive service operation is the problem management process that aims to investigate the root causes of incidents reported by users and customers. If a service desk worker must answer phone calls while doing proactive problem management, it is quite likely that 'fire-fighting' takes priority. It is the manager's responsibility to ensure that proactive teams can focus on identifying repeating incidents and creating high quality problem solutions. It would be even more proactive to monitor infrastructure (networks, servers) so that problems could be identified prior to causing incidents. We also identified that ITIL v2 provides better support for proactive problem management than $v 3$. It may be helpful to define distinct problem management procedures for a) problems that a problem management team can solve, b) problems that need a solution from a third party and c) problems that need to be resolved through change management.

Recommendation 7: Ensure that service operation processes have clearly defined interfaces to other service management processes. Our study revealed that poor communication and lack of cooperation between different service operation processes is likely to result in suboptimal outcomes. IT service providers should pay special attention to the interfaces between incident management, problem management and change management. According to ITSM principles, a problem management team should address the problems that require code changes by opening a Request for Change. Additionally, improvement suggestions logged by the service desk should be considered through the change management process. 
Recommendation 8: Identify and differentiate aspects of improvement. We observed that the terminology related to improvements between standards and frameworks varies considerably. First, both 'continuous improvement' and 'continual improvement' terms are used by companies. We recommend using 'continual' for companies that perform ITSM process improvement in stages and that have periods of time between the stages when process improvement is not done. However, if the process improvement is truly continuous, such as running continuous services without any interruption, one could use 'continuous improvement'. At the moment, it seems that the term 'CSI' is used for all types of improvements such as service delivery improvements, improvement of services, improvement of products, and improvement of processes.

\section{Theoretical implications}

Based on the extracted themes, we have confirmed prior findings on ITIL adoption, in particular, the important role of external consultants (Iden \& Eikebrokk, 2013), integration of ITSM tools (ISO, 2005), allocation of roles and responsibilities, difficulties in measuring and reporting metrics (Cater-Steel, Tan, Toleman, Rout, \& Shrestha, 2013), process integration (Shang \& Shu-Fang, 2010), and the need for more detailed guidance on conducting CSI in practice. Instead of 'cherry picking' process activities, providers should aim to consistently implement all required processes. There is a need for more theory-based conceptual models of service operation. Currently, reactive modes dominate proactive modes in service operation. King and Teo (2000) showed the positive impact of proactive modes in strategic information system planning. Further research could consider proactive versus reactive approaches across the entire ITSM lifecycle: Service Strategy, Design, Transition, Operation and CSI. An important variable to consider in future research of ITSM is proactivity. Proactivity could be seen as an organizational characteristic but also as a process characteristic. Service operation research should also discuss in more detail how to measure proactivity.

\section{Limitations and further research}

There are certain limitations related to this study. First, the recommendations to practitioners have not been validated with the case organizations. These recommendations reflect what the research team learned from the three cases and how ITSM best practices could be applied in a more efficient way by IT service provider organizations. Second, the case study method has received criticism regarding the generalizability of results. We acknowledge this limitation that the findings from three cases cannot be generalized to the entire population of IT service providers. We cannot demonstrate high validity but by maximizing clarity and agreement we believe validity is more, rather than less likely (Ryan \& Bernard, 2003). According to Yin (1994), case studies allow generalizing the results to some broader theory. The goal of this paper was to extend the theory of ITSM by contributing to the field of service operations. Third, we used a qualitative approach to explore case organizations' service operation activities. A large scale survey might have provided new viewpoints on IT service operation. Fourth, it is too early to judge the lasting impact of 'quick wins' initiatives: the issue of sustainment in improvement initiatives could be addressed through longitudinal studies.

Further research could also investigate the maturity of IT service operation processes. We call for more empirical research on ITSM and IT service operations in particular. Especially, the use of cloud outsourcing is growing and creating critical dependencies between 
IT operations providers and individuals. The use of cloud service portals may cause challenges for service operation activities. Service desk teams need to be aware of changes carried out in the customer environments.

\section{Contributions to research and practice}

Notwithstanding these limitations, this research makes significant contributions to both research and practice. The field of IT service operation management is ill-defined and this exploratory analysis is an attempt to move one step closer to define the phenomenon. These concepts may guide other researchers in the field in elaborating on the phenomenon. In line with the view expressed by Rosemann and Vessey (2008), we hope our research efforts result in highly practical applicability for stakeholders, such as IT service operation managers. Practitioners may particularly benefit from the recommendations provided. For instance, IT service managers can use this research to become aware of the IT service operation activities and challenges experienced by other service providers and develop a proactive approach leading to effective programs for improvement that will result in enhanced business value and customer satisfaction.

\section{ACKNOWLEDGMENTS}

ITIL ${ }^{\circledR}$ and IT Infrastructure Library ${ }^{\circledR}$ are registered trademarks of Axelos Limited. COBIT ${ }^{\circledR}$ is a registered trademark of ISACA. Microsoft owns the copyrights of Microsoft Operation Framework. CMMI ${ }^{\circledR}$ is registered trademark of Carnegie Mellon Institute.

\section{REFERENCES}

Al Mourad, M. B., \& Johari, R. (2014). Resolution of Challenges that are Facing Organizations before ITIL Implementation. International Journal of Future Computer and Communication, 3(3), 210 215.

April, A., Huffman Hayes, J., Abran, A., \& Dumke, R. (2005). Software Maintenance Maturity Model (SMMM): The Software Maintenance Process Model. Journal of Software Maintenance and Evolution: Research and Practice, 17(3), 197-223. doi:10.1002/smr.311

Bardhan, I. R., Demirkan, H., Kannan, P. K., Kauffman, R. J., \& Sougstad, R. (2010). An Interdisciplinary Perspective on IT Services Management and Service Science. Journal of Management Information Systems, 26(4), 13-64.

Barlow, J., \& Stewart, P. (2004). Branded Customer Service: The New Competitive Edge. San Francisco, USA: Berrett-Koehler Publishers.

Baskerville, R. L. (1999). Investigating Information Systems with Action Research. Communications of the AIS, 2, 1-31.

Beath, C. M., \& Straub, D. W. (1989). Managing Information Resources at the Department Level: An Agency Perspective. Paper presented at the Hawaii International Conference on System Sciences (22nd), Hawaii.

Cabinet Office. (2011a). ITIL Continual Service Improvement. UK: The Stationary Office.

Cabinet Office. (2011b). ITIL Service Design. UK: The Stationary Office.

Cabinet Office. (2011c). ITIL Service Operation. UK: The Stationary Office.

Cabinet Office. (2011d). ITIL Service Strategy. UK: The Stationary Office.

Cabinet Office. (2011e). ITIL Service Transition. UK: The Stationary Office. 
Caldeira, J., \& Brito e Abreu, F. (2008). Influential Factors on Incident Management: Lessons Learned From a Large Sample of Products in Operation. In A. Jedlitschka \& O. Salo (Eds.), Product-Focused Software Process Improvement: 9th International Conference, PROFES 2008 Monte Porzio Catone, Italy, June 23-25, 2008 Proceedings (pp. 330-344). Berlin, Heidelberg: Springer Berlin Heidelberg.

Card, D. N. (1998). Learning From Our Mistakes with Defect Causal Analysis. IEEE Software, 15(1), 56-63. doi:10.1109/52.646883

Cater-Steel, A., Tan, W.-G., Toleman, M., Rout, T., \& Shrestha, A. (2013). Software-Mediated Process Assessment in IT Service Management. Communications in Computer and Information Science

Cavalcante, V. F., Pinhanez, C. S., Paula, R. A. d., Andrade, C. S., Souza, C. R. B. d., \& Appel, A. P. (2013). Data-Driven Analytical Tools for Characterization of Productivity and Service Quality Issues in IT Service Factories. Journal of Service Research, 16, 295-310. doi:10.1177/1094670513480559

COBIT5. (2012). Control Objectives for Information and Related Technology: COBIT 5: ISACA.

Davenport, T. H., \& Short, J. E. (1990). The New Industrial Engineering: Information Technology and Business Process Redesign. Sloan Management Review, 31, 11-27.

Eisenhardt, K. M., \& Graebner, M. E. (2007). Theory Building from Cases: Opportunities and Challenges. Academy of Management Journal, 50(1), 25-32. doi:10.5465/AMJ.2007.24160888

Gacenga, F., Cater-Steel, A., \& Toleman, M. (2010). An International analysis of IT service management benefits and performance measurement. Journal of Global Information Technology Management, 13(4), 28-63.

Goldkuhl, G. (2008). Practical Inquiry as Action Research and Beyond. Paper presented at the 16th European Conference on Information Systems.

Harris, S. J. (1996). Proactive Service Management: Leveraging Telecom Information Assets for Competitive Advantage. Paper presented at the Network Operations and Management Symposium.

Heikkinen, S., \& Jäntti, M. (2012). Establishing a continual service improvement model: A case study. In D. Winkler, R. O'Connor, \& R. Messnarz (Eds.), Communications in Computer and Information Science: Systems, Software and Services Process Improvement (Vol. 301, pp. 61-72). Berlin Heidelberg: Springer

Hirmanpour, I., \& Schofield, J. (2003). Defect Management Through the Personal Software Process. The Journal of Defense Software Engineering, 150, 17-20.

Hochstein, A., Zarnekow, R., \& Brenner, W. (2005). ITIL as Common Practice Reference Model for IT Service Management: Formal Assessment and Implications for Practice. Paper presented at the Proceedings of the 2005 IEEE International Conference on e-Technology, e-Commerce and eService (EEE'05), Washington DC, USA.

Huang, M.-H., \& Rust, R. T. (2013). IT-Related Service: A Multidisciplinary Perspective. Journal of Service Research, 16(3), 251-258. doi:10.1177/1094670513481853

Huberman, A. M., \& Miles, M. B. (1994). Data Management and Analysis Methods (pp. 428-444). Thousand Oaks, CA: Sage Publications.

Iden, J., \& Eikebrokk, T. R. (2013). Implementing IT Service Management: A Systematic Literature Review. International Journal of Information Management, 33(3), 512-523. doi:http://dx.doi.org/10.1016/j.ijinfomgt.2013.01.004

Iden, J., \& Langeland, L. (2010). Setting The Stage for a Successful ITIL Adoption: A Delphi Study of IT Experts in the Norwegian Armed Forces. Information Systems Management, 27(2), 103-112. doi:10.1080/10580531003708378

ISO. (2004). ISO/IEC 2004, ISO/IEC 15504-2:2004 - Information Technology - Process Assessment Part 2: Performing an Assessment. Geneva, Switzerland: International Organization for Standardization. 
ISO. (2005). ISO 9000:2005 Quality Management Systems Fundamentals and vocabulary: ISO Copyright Office.

ISO. (2010). ISO/IEC 20000:1 Part 1: Service management system requirements: ISO/IEC JTC 1 Secretariat.

ISO. (2012). ISO/IEC TS 15504-8:2012 Information Technology - Process Assessment Part 8: An exemplar process assessment model for IT service management: ISO/IEC TC JTC1/SC7 Secretariat.

Jantti, M., Rout, T., Wen, L., Heikkimen, S., \& Cater-Steel, A. (2013). Exploring the Impact of IT Service Management Process Improvement Initiatives: A Case Study Approach. Paper presented at the Spice 2013.

Järveläinen, J. (2013). IT incidents and business impacts: Validating a framework for continuity management in information systems. International Journal of Information Management, 33(3), 583-590. doi:http://dx.doi.org/10.1016/j.ijinfomgt.2013.03.001

Kajko-Mattsson, M. (1998). A Conceptual Model of Software Maintenance. Paper presented at the Proceedings of the 20th international conference on Software Engineering, Washington, DC, USA.

Kajko-Mattsson, M. (2002). Problem Management Maturity within Corrective Maintenance. Journal of Software Maintenance and Evolution: Research and Practice, 14(3), 197-227. doi:10.1002/smr.252

Kerr, D. S., \& Murthy, U. S. (2013). The importance of the CobiT framework IT processes for effective internal control over financial reporting in organizations: An international survey. Information \& Management, 50(7), 590-597. doi:http://dx.doi.org/10.1016/j.im.2013.07.012

King, W. R., \& Teo, T. S. H. (2000). Assessing the Impact of Proactive Versus Reactive Modes of Strategic Information Systems Planning. Omega, 28(6), 667-679. doi:http://dx.doi.org/10.1016/S0305-0483(99)00079-1

Koch, H., \& Gierschner, C. (2007). Advantages of an ITIL-Based Process Framework in a Complex SAP® System Landscape. Paper presented at the 4th IEEE Workshop on Intelligent Data Acquisition and Advanced Computing Systems: Technology and Applications (IDAACS 2007).

Kotter, J. P. (1996). Leading Change: Harvard Business Press.

Latif, A. A., Din, M. M., \& Ismail, R. (2010, 19-21 March 2010). Challenges in Adopting and Integrating ITIL and CMMI in ICT Division of a Public Utility Company. Paper presented at the 2nd International Conference on Computer Engineering and Applications (ICCEA), Bali Island.

Markworth, J. (2005). Driving a New IT Reality. Viewpoint. Retrieved from

Marrone, M., Gacenga, F., Cater-Steel, A., \& Kolbe, L. M. (2014). IT Service Management: A Crossnational Study of ITIL Adoption. Communications of the Association of Information Systems (CAIS), 39(49), 865-892.

Marrone, M., \& Kolbe, L. (2011). Uncovering ITIL Claims: IT Executives' Perception on Benefits and Business-IT Alignment. Information Systems \& e-Business Management, 9(3), 363-380. doi:10.1007/s10257-010-0131-7

Mays, R. G., Jones, C. L., Holloway, G. J., \& Studinski, D. P. (1990). Experiences with Defect Prevention. IBM Systems Journal, 29(1), 4-32. doi:10.1147/sj.291.0004

McNaughton, B., Ray, P., \& Lewis, L. (2010). Designing an evaluation framework for IT service management. Information \& Management, 47(4), 219-225. doi:http://dx.doi.org/10.1016/j.im.2010.02.003

McNiff, J. (2013). Action Research: Principles and Practice. Abingdon: Routledge.

Mohamed, M. S., Ribière, V. M., O'Sullivan, K. J., \& Mohamed, M. A. (2008). The Re-Structuring of the Information Technology Infrastructure Library (ITIL) Implementation Using Knowledge Management Framework. VINE, 38(3), 315-333. doi:doi:10.1108/03055720810904835 
Niessink, F., \& Van Vliet, H. (1998). Towards Mature IT Services. Software Process: Improvement \& Practice, 4(2), 55-71.

Niessink, F., \& van Vliet, H. (2000). Software Maintenance From a Service Perspective. Journal of Software Maintenance: Research \& Practice, 12(2), 103-119.

Orta, E., Ruiz, M., Hurtado, N., \& Gawn, D. (2014). Decision-Making in IT Service Management: a Simulation Based Approach. Decision Support Systems, 66, 36-51. doi:http://dx.doi.org/10.1016/j.dss.2014.06.002

Parasuraman, A., Berry, L. L., \& Zeithaml, V. A. (1991). Refinement and Reassessment of the Servqual Scale. Journal of Retailing, 67(4), 420.

Pedersen, K., Kræmmergaard, P., Lynge, B. C., \& Schou, C. D. (2010). ITIL Implementation: Critical Success Factors a Comparative Case Study Using the BPC Framework. Journal of Information Technology Case \& Application Research, 12(2), 11-35.

Pereira, R., \& Silva, M. M. d. (2011). A Maturity Model for Implementing ITIL V3 in Practice. Paper presented at the 15th IEEE International Enterprise Distributed Object Computing Conference Workshops (EDOCW).

Pollard, C., \& Cater-Steel, A. (2009). Justifications, Strategies, and Critical Success Factors in Successful ITIL Implementations in U.S. and Australian Companies: An Exploratory Study. Information Systems Management, 26(2), 164-175. doi:10.1080/10580530902797540

QAI. (1995). A Software Defect Management Process. Retrieved from http://www.defectmanagement.com/defectmanagement/index.htm

Rosemann, M., \& Vessey, I. (2008). Toward Improving the Relevance of Information Systems Research to Practice: the Role of Applicability Checks. MIS Quarterly, 32(1), 1-22.

Ryan, G. W., \& Bernard, H. R. (2003). Techniques to Identify Themes. Field Methods, 15(1), 85-109. doi: $10.1177 / 1525822 \times 02239569$

Scott, D. (2003). IT Operations Management Is Undergoing Transformation. Retrieved from https://www.gartner.com/doc/396258/it-operations-management-undergoing-transformation

Shang, S. S. C., \& Shu-Fang, L. (2010). Barriers to Implementing ITIL-A Multi-Case Study on the Service-Based Industry. Contemporary Management Research, 6, 53-70.

Tan, W., Cater-Steel, A., \& Toleman, M. (2009). Implementing IT service management: a case study focussing on critical success factors. Journal of Computer Information Systems (JCIS), 50(2), 112.

Trauth, E. M., \& Jessup, L. M. (2000). Understanding Computer-Mediated Discussions: Positivist and Interpretive Analyses of Group Support System Use. MIS Quarterly, 24(1), 43-79. doi:10.2307/3250979

Walker, R. H., Craig-Lees, M., Hecker, R., \& Francis, H. (2002). Technology-Enabled Service Delivery: An Investigation of Reasons Affecting Customer Adoption and Rejection. International Journal of Service Industry Management, 13(1), 91-106. doi:doi:10.1108/09564230210421173

Yin, R. (1994). Case Study Research: Design and Methods. Beverly Hills, CA: Sage.

Zhang, L.-J., Cai, H., \& Zhang, J. (2007). Services Computing: Tsinghua University Press, Beijing and Springer-Verlag GmbH Berlin Heidelberg 